\title{
Status epilepticus, hypothermia and metabolic chaos in a man with agenesis of the corpus callosum
}

\author{
MH JOHNSON, SN JONES
}

From the Department of Neurology and the Intensive Care Unit, the Middlesex Hospital, London, UK

SUMMARY A case of hypothermia and metabolic derangement in a 60-year-old man following a period of status epilepticus is reported. A CT head scan performed subsequently demonstrated agenesis of the corpus callosum. Hypercalcaemia which has not been reported before was a prominent abnormality in the metabolic profile.

In 1969, Shapiro et al ${ }^{1}$ described an association in two patients between spontaneous attacks of hypothermia and agenesis of the corpus callosum. This association has been reported subsequently in eight other cases, ${ }^{2-9}$ some of which were intensively investigated both during, and in between, attacks of hypothermia. It is accepted that agenesis of the corpus callosum does not, of itself, cause the disturbance of temperature control, but there are always associated developmental abnormalities involving midline structures which presumably interfere with temperature control mechanisms. In the one pathological study adequately reported, ${ }^{3}$ fibrosis of the anterior hypothalamus with neuronal loss was described, and experimental studies have suggested that this structure may be concerned with heatdissipating mechanisms. ${ }^{10}$ In these cases, the episodes of hypothermia have varied from a few minutes or hours, to more than one week in duration, and there has been much discussion as to whether they could be epileptic events. In the early reports, this was assumed to be the case, and the name diencephalic epilepsy was applied to such cases. Some seemed to respond to anticonvulsants, but in more recently studied cases, these were ineffective, and other mechanisms were suggested. Profound metabolic and haematological disturbances have been reported in many of the patients usually

Address for reprint requests: Dr Michael Johnson, The National Hospitals for Nervous Diseases, Queen Square, London WC1N 3 BG, UK.

Received 27 July 1984 and in revised form 20 October 1984. Accepted 3 November 1984 occurring at the time of the hypothermic episodes. No mechanism for these has been proposed, and investigations after recovery have failed to show persisting abnormalities.

We report a man with agenesis of the corpus caf losum who developed a single episode of hypothero mia with a variety of metabolic disorders during $\mathrm{\Phi}$. period of status epilepticus, after which he rece vered. He had never had disturbances of temperas ture control before, even in association with a previg ous episode of status epilepticus.

\section{Case report}

A 60-year-old man was admitted to hospital following a fall which caused a fracture of his left scapula. He did not injure his head or lose consciousness. He had suffered from generalised convulsions since the age of eleven years, but $\triangle$ these were well controlled on a combined preparation of $\overrightarrow{\vec{B}}$ phenobarbitone $50 \mathrm{mg}$ and phenytoin $100 \mathrm{mg}$ thrice daily.

His medical records since 1948 revealed only a single episode of status epilepticus in 1979 , which necessitated hospital admission for $\mathbf{4 8}$ hours. On that occasion, he was found to have an extensor plantar response on the right, and investigations revealed a normal temperature, normal T4 level and a normochromic normocytic anaemia $(\mathrm{Hb}=-\overline{0}$ $11.6 \mathrm{~g} / \mathrm{dl}$ ) for which no cause was determined. When reviewed subsequently he was fully recovered. He was said to have always been of low intelligence but had worked conscientiously all his life, running his own successful greengrocery business. After six days in hospital, he $ㅇ$ appeared to be recovering from his fall, and investigations $D$ showed satisfactory anticonvulsant and T4 levels. He then 음 developed brief generalised seizures, often associated with rigidity, which became more frequent. Clinical examina- $\sigma$ tion demonstrated persistent signs of a right hemiparesis $\mathrm{N}$ and a right extensor plantar response. Eventually, these 

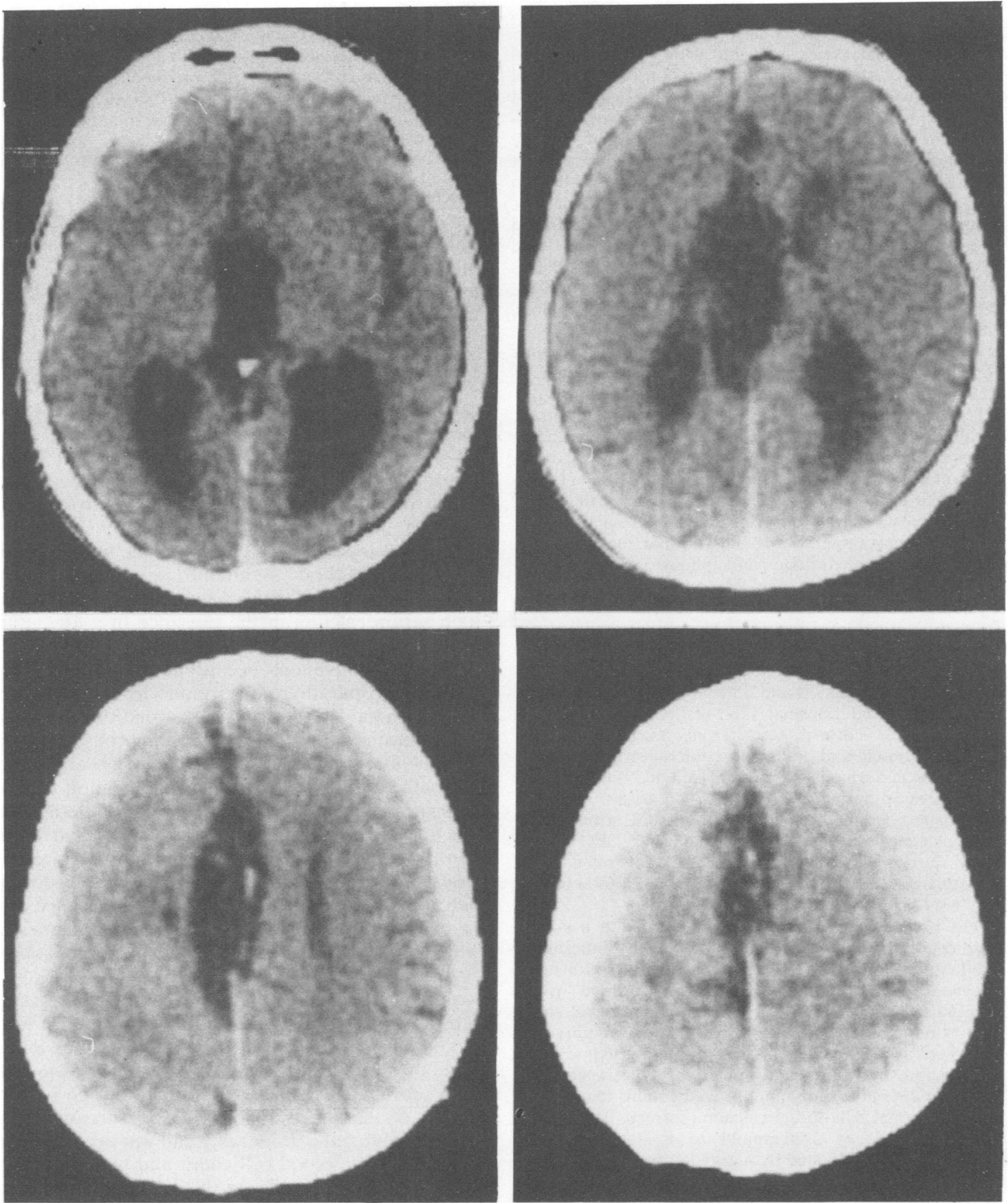

Fig CT scan showing agenesis of the corpus callosum.

attacks became almost continuous over a 24 hour period, and failed to respond to intravenous diazepam or chlormethiazole. In association with this, his interictal conscious

level deteriorated such that he was not responding to painful stimuli.

At this stage he was transferred for neurosurgical 
assessment at the Middlesex hospital. On arrival there, fourteen days after the fall, he was noted to be normotensive with a sinus tachycardia, but within an hour he had deteriorated further and became unresponsive, cold (rectal temperature $=29^{\circ} \mathrm{C}$ ), pale and hypotensive (systolic blood pressure $=30-50 \mathrm{~mm} \mathrm{Hg})$ with a sinus bradycardia $(40-$ 60 b.p.m.). His respiratory effort was inadequate and he was intubated and artifically ventilated. On examination at this stage, the eyes were in the primary position, with no reflex movements, and with $2 \mathrm{~mm}$ pupils showing a poor response to light. There was twitching of the tongue and frequent jerking of the right arm and leg. The limbs were flaccid with no response to painful stimuli and the reflexes were exaggerated on the right with bilateral extensor plantar responses. There was no clinical evidence of blood loss. Investigations on admission showed anaemia $(\mathrm{Hb}=$ $9.0 \mathrm{~g} / \mathrm{dl}, \mathrm{PCV}=0.28 \%, \mathrm{WCC}=4.6 \times 10^{9} / \mathrm{l}$ ) with uraemia (urea $=29.5 \mathrm{mmol} / \mathrm{l}$, creatinine $=184 \mathrm{~mol} / \mathrm{l}$, sodium $=$ $150 \mathrm{mmol} / \mathrm{l}$ and normal potassium). Calcium (corrected) $=$ $2.96 \mathrm{mmol} / \mathrm{l}$ and albumin $=19 \mathrm{~g} / \mathrm{l}$. Serum phosphate, alkaline phosphatase, folate, serum iron, total iron binding capacity and immunoglobulins were normal. The aspartate aminotransferase level was initially elevated $484 \mathrm{iu} / \mathrm{l}$ (normally less than $40 \mathrm{iu} / \mathbf{l}$ ), and rapidly fell to normal after which there was a transient rise in the alkaline phosphatase level to a maximum of $448 \mathrm{iu} / \mathrm{l}$ (normal range $=100$ $280 \mathrm{iu} / \mathrm{l}$ ). Phenobarbitone and phenytoin levels were within the therapeutic range. The initial endocrine investigations showed that the T4 level had fallen to $41 \mathrm{nmol} / \mathrm{l}$ from the normal level just after his fall but the TSH was not elevated at $3.8 \mathrm{mU} / \mathrm{l}$. Subsequent investigation of the hypothalamic-pituitary axis after neurological improvement showed normal T4 and T3 levels (T4 = $74 \mathrm{nmol} / \mathrm{l} \mathrm{T} 3$ $=21 \mathrm{nmol} / \mathrm{l}$ ) and a normal TRH test, LH, FSH, LH-RH test, prolactin, cortisol, testosterone, magnesium, parathyroid hormone and oral glucose tolerance test (OGTT). Basal growth hormone was normal $(5.3 \mathrm{mU} / \mathrm{l})$ but failed to be suppressed during OGTT on two occasions.

Plain radiographs were normal but a CT scan demonstrated agenesis of the corpus callosum (fig). EEG showed frank seizure activity with evidence of a left sided origin. Cerebrospinal fluid examination contained a total protein of $0.8 \mathrm{~g} / \mathrm{l}$ but was otherwse normal.

His hypotension responded dramatically to a volume load of 51 of colloid (initial CVP-5), his hypothermia to gradual rewarming and his status epilepticus to intravenous phenytoin and a thiopentone infusion titrated with a cerebral function monitor. His haemoglobin level stabilised at $6.6 \mathrm{~g} / \mathrm{l}$ following the colloid load and required a 4 unit transfusion. A bone marrow aspirate was hypocellular, with suppression particularly of erythropoiesis. Over the next two days his condition improved and his temperature rose to normal. His serum calcium (corrected) fell slowly from its peak of $2.96 \mathrm{mmol} / \mathrm{l}$ to a stable value of $2.30 \mathrm{nmol} / \mathrm{/}$ accompanied by a gradual rise in the albumin to $32 \mathrm{~g} / \mathrm{l}$. All other haematological and biochemical abnormalities corrected. However despite intravenous and nasogastric feeding, he showed loss of muscle bulk, and, when testing became possible, he had generalised weakness without loss of reflexes. EMG showed small polyphasic potentials consistent with a diffuse myopathy.

There was no radiographical evidence of metabolic bone disease. One month after the fall, he was well enough to be discharged to the referring hospital, and after a period of further physiotherapy, he was able to go home with a mild right hemiparesis and moderate proximal myopathy. On outpatient review one year later, he had no neurological abnormalities and no haematological or metabolic abnormalities. He remains on anticonvulsants.

\section{Discussion}

This patient developed hypothermia and widespread metabolic and haematological disturbances in association with a period of status epilepticus following a fall. His fits were reasonably well controlled before and after this episode and he had previously had an episode of status epilepticus without temperature or metabolic disturbance. No precipitating cause for this episode is apparent. As the fits became more frequent his general condition and conscious level deteriorated, and it is impossible to know whether this was due to the frequent fits, to the drugs which were given to attempt to control the fits, or to a developing metabolic disturbance. After transfer to the Middlesex Hospital, he was found to have a low body temperature and deranged metabolism. Of particular interest is the initiall $\bar{b}$ high serum calcium in the presence of a low albu哩 $\mathrm{min}$. The calcium samples were all taken in the fast? ing state with venous occlusion. The serum mag nesium and parathyroid hormone levels were norsmal. In none of the previously recorded cases o\& hypothermia with agenesis of the corpus callosune has an abnormal calcium level been observed. A $\overline{\bar{\sigma}}$. the same time, there was some elevation of the or plasma sodium and urea, which undoubtedly was due to fluid depletion. Hyponatraemia occurred in two cases $^{7-9}$ but the sodium was normal in other cases. Low serum albumin has not been reported before. Parallel with the metabolic disturbance and recovery, there was the development of anaemia which appears to have resulted from suppression of erythropoiesis in the marrow. Anaemia, usuaily with pancytopenia, has occurred in three previously reported cases. ${ }^{137}$ It is of interest that, in this patient, a low haemoglobin had been recorded at the time of status epilepticus three years previously, with subsequent recovery to normal, but no further details of this are available. On this occasion, the haemoglobin fell considerably and was accompanied by a low white blood cell count and platelet count. Endocrinological studies in this, as in other patients in whom hypothermia occurred in association with agenesis of the corpus callosum, did not show any striking abnormality.

The first thyroxine level was marginally low at a time when the albumin level was low and the total 
globulin level was not measured. Subsequently, all studies were normal apart from the failure of growth hormone suppresion during an oral glucose tolerance test.

The development of a myopathy has not been described previously as part of this syndrome. Its origin is also obscure, but it could perhaps have resulted from the effects of the metabolic disturbances upon muscle. Like everything else, this recovered, although rather more slowly. Finally this case differs from those previously described in that hypothermia appears to have occurred only once in the patient's life. Much attention has been paid in previous reports to the origin of the hypothermia and, in particular, whether it could result from epileptic activity. The majority of writers have thought that this is unlikely, and, in this case, the fact that it had not occurred during a previous episode of generalised status epilepticus is perhaps also against this. However, recovery occurred when the fits were terminated, although ictal activity was still found on EEG and observed clinically during the recovery phase. The temperature control system is thought to be affected as a result of abnormal development of the anterior hypothalamus, which was found in one case where an adequate autopsy was performed. ${ }^{38}$ It is suggested that the thermostat is incorrectly set so that heat losing mechanisms are inappropriately deployed. There are no data available which would elucidate the reason for this, or explain why, in some cases, it tends to occur intermittently, with periods of normal temperature control in between. The effects of raising the body temperature from the hypothermic level using pyrogens or air-conditioned beds has been described in some cases. ${ }^{11112}$ In most patients attempts at rewarming caused inappropriate sweating until the body temperature fell again to hypothermic levels. In our case, inappropriate sweating was not observed and the temperature rose uneventfully to normal using rewarming methods.

The variety of disturbances in this patient emphasises the dependance of many homoeostatic mechanisms on intact cerebral function and, in particular, on function of the hypothalamus.
We are grateful to Dr CJ Earl för permission to report this case and for his helpful comments in the preparation of the manuscript.

\section{References}

' Shapiro WR, Williams GH, Plum F. Spontaneous recurrent hypothermia accompanying agenesis of the corpus callosum. Brain 1969;92:423-36.

${ }^{2}$ Guihard J, Velot-Lerou A, Poitrat C, Laloum D, L'Hirondel J. Hypothermie spontanée récidivante avec agénésie du corps calleux. Syndrome de Shapiro (nouvelle observation). Ann Pédiatr (Paris) 1971; 18:645-56.

${ }^{3}$ Noël P, Hubert JP, Ectors M, Franken L, FlamentDurand J. Agenesis of the corpus callosum associated with relapsing hypothermia. Brain 1973;96:359-68.

${ }^{4}$ Dutau G, Carrière J-P, Rochiccioli P. Hypothermie spontanée récidivante avec hypoplasie du corps calleux. Pediatrie 1975;30:117-27.

${ }^{5}$ Sadowsky C, Reeves AG. Agenesis of the corpus callosum with hypothermia. Arch Neurol 1975;32:7746.

${ }^{6}$ Carr-Locke D, Millac P. Diencephalic epilepsy in a patient with agenesis of the corpus callosum confirmed by computerised axial tomography. $J$ Neurol Neurosurg Psychiatry 1977;40:808-14.

' Summers GD, Yound AC, Little RA, Stoner HB, Forbes WSTC, Jones RAC. Spontaneous periodic hypothermia with lipoma of the corpus callosum. $J$ Neurol Neurosurg Psychiatry 1981;44:1094-9.

${ }^{8}$ Lechevalier B. Un case anatomo-clinique d'agenesie du corps calleux avec hypothermie spontanee recidivante. Rev Neurol (Paris) 1979;135:379.

${ }^{9}$ Mooradian AD, Morley GK, McGeachie R, Ludgren S, Morley EJ. Spontaneous periodic hypothermia. Neurology (NY) 1984;34:79-82.

${ }^{10}$ Myers RD, Yaksh TL. Control of body temperature in the unanaesthetised monkey by cholinergic and aminergic systems in the hypothalamus. $J$ Physiol (Lond) 1969;202:483-500.

1 Thomas DJ, Green ID. Periodic hypothermia. Br Med J 1973;2:696-7.

${ }^{12}$ Fox RH, Wilkins DC, Bell JA et al. Spontaneous periodic hypothermia: Diencephalic epilepsy. $\mathrm{Br}$ Med J 1973;2:693-5. 